\title{
A APRENDIZAGEM DA CRIANÇA: ASPECTOS SOBRE SURDEZ E INCLUSÃO ESCOLAR
}

Marcela Corrêa Tinti

Centro Universitário “Antonio Eufrásio de Toledo”, Presidente Prudente, SP. E-mail: marcellatinti@gmail.com

\section{RESUMO}

Diante das expectativas que enredam a sociedade contemporânea, a educação de qualidade para todos compõe um rol de destaque, principalmente no que tange o provimento da inclusão escolar. Por isso, nesse artigo nosso objetivo é aprofundar discussões com a finalidade de elucidar sobre concepção da aprendizagem da criança com Surdez ou Deficiência Auditiva (DA) a fim de promover práticas inclusivas. De cunho qualitativo, analisamos os pressupostos que substanciam o desenvolvimento de práticas escolares inclusivas para estudantes com Surdez. Entre os aspectos observados, evidenciamos que apesar dos indicativos favoráveis para a inclusão escolar, os pressupostos com maior ênfase das pesquisas brasileiras acabam por enfatizar práticas que perpassam os conceitos de Educação Especial e Adaptação Curricular. Entretanto, compreendemos que as práticas inclusivas ultrapassam as perspectivas homogêneas, e que a partir da valorização das diferenças, poderemos propor o desenvolvimento da aprendizagem de todos.

Palavras-chave: Educação para todos, Aprendizagem da criança com surdez, Inclusão escolar.

\section{CHILD LEARNING: ASPECTS ABOUT DEAFNESS AND SCHOOL INCLUSION}

\begin{abstract}
Faced of the expectations that a contemporary idea is made, quality education for all levels of education, especially with regard to school inclusion. For this reason, the article is being discussed for the purpose of elucidating on the subject of education. Of qualitative character, analysis the assumptions that substantiate of development of students did the students to students with Deafness. Abstract: The Required Requirements for Ins Graph the students of the higher students of the students are empathizing the perpassam of the performer of Education Special and Curricular Adaptation. However, since inclusive practices can be applied in the form of homogeneous ones, since they can promote the differentiation of differences, we can propose the development of the learning of all.
\end{abstract}

Keywords: Education for all, Learning of child with deafness, School inclusion 


\section{INTRODUÇÃO}

Compreender a sociedade contemporânea a ponto de suprir as necessidades e expectativas dos vários setores que a compõem é um desafio complexo. Nesse viés promover educação para todos têm composto o escopo das pesquisas no Brasil, principalmente diante a expansão quantitativa de vagas e do processo de democratização do ensino público.

O esse viés de promoção da educação, principalmente, alicerçado principalmente no que preconiza o Art.5o da Constituição Federal Brasileira de 1988, do aspecto da "qualidade para todos", promoveu o rompimento do paradigma educacional e corroborou para a instauração das discussões com enfoque maior no que tange a aprendizagem dos estudantes. Esse processo, de acordo com Leite e Di Giorgi (2004), colocou em xeque a concepção primária dos espaços escolares que enredavam os pressupostos sobre o ensino, aprendizagem e o papel da instituição escolar: a educação nunca foi para todos, e não tinha a premissa de ser.

Na perspectiva de se compreender os espaços e pertencimentos, a aprendizagem torna-se o epicentro dos processos, substânciando as discussões de Patto $(1996 ; 1998)$ sobre a produção do fracasso escolar, as de Mantoan (2004) sobre o processo de resignificação do espaço escolar, as de Valente (2002) sobre a propositura do uso de tecnologias, as de Schlünzen (2015) sobre a propositura de práticas significativas, e as de Pimenta (1999; 2013) sobre a composição da identidade profissional do professor.

A essas ideias, Tinti (2016) descreveu em sua tese que as concepções que fortaleceram a percepção e promoção da democratização do espaço escolar, apesar de qualitativas e necessárias, mostraram-se, diante a complexidade do contexto atual, ainda insuficiente. Isso porque estão enredadas à oferta de vagas e inserção dos estudantes nos espaços educacionais, mas nem sempre contempla e proporciona valorização das práticas pedagógicas, fortalecimento dos espaços, formação continuada de qualidade, para que todos possam, efetivamente, aprender.

A educação, direito de todos e dever do Estado e da família, será promovida e incentivada com a colaboração da sociedade, visando ao pleno desenvolvimento da pessoa, seu preparo para o exercício da cidadania e sua qualificação para o trabalho. (BRASIL, art. 205, 1988).

Entre os grupos atualmente inseridos nos espaços escolares, os Estudantes Público Alvo da Educação Especial (EPAEE), caracterizados como estudantes com deficiências, transtornos e/ou dificuldades de aprendizagem, compõem grupo de destaque. A etiologia da palavra "deficiência" apresenta a "insuficiência ou ausência de, perda de valor, falha, fraqueza, falta", e tais características se evidenciam em espaço escolar, que teve por embasamento primo, ressaltar o desenvolvimento de valores, conceitos e aprendizagens de maneira que se superasse a eficiência humana. Mantoan destaca em seus estudos que, pensar em uma escola para todos, é por premissa, contemplar a superação do conceito de eficiência. Isso, ultrapassa a perspectiva produtivista de valorização de resultados para a consolidação de espaços que primem pelo desenvolvimento humano.

Nesse contexto, os estudantes com Surdez ou Deficiência Auditiva (DA) apresentam complexidade com destaque. Os termos, caracterizações, cultura e língua própria colocam a margem a história da Comunidade Surda, e enfatizam o desencontro de informações e práticas das áreas de saúde e educação. É importante salientar que, de acordo com o Instituto Brasileiro de Geografia e Estatística (IBGE) aproximadamente 5\% da população brasileira apresentam laudo de DA.

Por isso, refletir sobre educação é também compreender o desenvolvimento da criança com Surdez. Um processo que não está condicionado apenas aos assuntos que destacam limites, dificuldades e pré-conceitos existentes, que permeiam as atitudes da sociedade. Compreender os pressupostos é parâmetro para a propositura de ações que auxiliem na superação de práticas e que possibilitem processos inclusivos. 
No que tange a composição da escola, pautada em práticas orais e visuais, refletir sobre estudantes com surdez é perceber um cenário difícil. Em virtude ao um sistema educacional fechado, muitos estudantes com Surdez sentem-se prejudicados, e às vezes, podem não ser estimulados de maneira que favoreça o desenvolvimento das habilidades cognitivas, sócioafetivas, linguísticas e político-cultural.

Nesse sentido, temos por objetivo disseminar as discussões e pesquisas sobre a consolidação da aprendizagem da criança com Surdez para promoção de práticas escolares inclusivas.

\section{METODOLOGIA}

A metodologia da pesquisa compõe os caminhos e escolhas que o pesquisador tomou no decorrer dos estudos. A pesquisa está correlata à percepção e compreensão do processo de desenvolvimento histórico e cultural, e por isso, apresenta por pressuposto a abordagem qualitativa como norteador. Esse tipo de pesquisa condiz com um análise crítica e meticulosa das áreas temáticas que enredam o objeto do estudo. Tem por finalidade propiciar discussão de um tema específico, cuja finalidade é aproximar o pesquisador com um assunto específico a partir de tudo o que foi vivenciado. (LAKATOS; MARCONI, 2004).

A discussão teórica enreda-se por pesquisas com temáticas que apresentam os descritores "aprendizagem da criança com surdez" "educação para todos" e "práticas inclusivas". Além dos descritores, buscou-se compreender as particularidades do espaço escolar por meio da articulação da ações desenvolvidas no Grupo de Pesquisa e a partir dos estudos que contemplam propostas para a composição da prática pedagógica.

Para o delineamento dos estudos utilizamos por base de dados o Literatura Latino Americano e do Caribe em Ciências Sociais e da Saúde (LILACS), o Scientific Eletronic Library OnLine (Scielo) e o Banco de Teses e Dissertações da Capes.

Os artigos foram selecionados a partir da variável de interesse, respeitando a temática e o objeto de pesquisa, totalizando 30 artigos. O processo de seleção aconteceu, tendo por base, leitura criteriosa dos materiais localizados nas bases de dados. Foram incluídas e analisadas apenas as publicações que atendiam ao objetivo da pesquisa, e que correspondiam ao delineamento teórico e epistemológico do estudo.

Mediante a sistematização dos dados encontrados, a análise aconteceu a partir da leitura integral de todo o material selecionado, tendo como aspectos orientadores para síntese da realidade do contexto educativo brasileiro. Dessa maneira, buscou-se compreender e ampliar o conhecimento sobre a aprendizagem da criança com Surdez, a fim de estabelecer articulação entre proposta teórica e as pesquisas estudadas, para assim inferir novas perspectivas.

\section{RESULTADOS}

Diante a temática do estudo que articula três descritores diretos, foram identificados, a partir de somática simples dos trabalhos disponíveis nos três bancos de dados utilizados, mais de dez mil trabalhos, entre artigos, trabalhos de conclusão de curso, dissertações e teses, articulados a todas as áreas de conhecimento.

Tal indício evidencia alta demanda dos processos investigativos para o provimento de práticas inclusivas e discussão sobre a composição da escola contemporânea no Brasil. Diante ao número elevado de publicações, foram selecionados trinta arquivos, compreendidos entre os anos de 2010 e 2016, que compreenderam a temática do estudo, com proximidade diretamente relacionada, cujo enfoque circunstancia inferências conceituais sobre: as reflexões para a construção da compreensão do objeto; a defesa da linha epistemológica sobre a abordagem das práticas educacionais; e a proposição de práticas escolares que vislumbrem o atendimento qualitativo para todo estudante. 


\section{DISCUSSÃO}

Os aspectos que correspondem à temática central, a ausência das capacidades auditivas, indicam nomenclaturas distintas e variáveis para a descriminação do processo de ouvir. Dentre as usuais, destacam-se dois termos: a Surdez e a Deficiência Auditiva. O tratamento, ou usabilidade das normativas corretas, configuram-se no respeito sobre os processos históricos de grupos que foram marginalizados ou excluídos. E, quando se trata sobre o aspecto da ausência de uma capacidade humana padrão, contida na deficiência, o uso de terminologias adequadas correspondem também sobre o reconhecimento e características específicas dos grupos, respeito e reconhecimento político e social. Por isso, as pesquisas que abordam os temas "inclusão escolar" "práticas inclusivas" "estudante público alvo da educação especial" visam proporcionar discussões e maneiras para construir conceitos que não subvalorize as habilidades e potencialidades das pessoas.

A partir desses preceitos, se considerarmos apenas a concepção orgânica, os termos "surdez e deficiência auditiva" são sinônimos. São usados para referir a qualquer tipo de perda auditiva, seja de grau leve, moderado, severo ou profundo, de um ou ambos ouvidos. Entretanto, a partir de análise conceitual e de aplicabilidade etiológica, percebemos que correspondem a uma perspectiva histórico-cultural que enfatiza os modos de vivenciar as diferenças dos grupos que se consolidam a partir da perca ou déficit da audição.

Os Surdos, caracterizados por letra maiúscula por alguns autores, não se consideram deficientes, utilizam uma língua própria (no Brasil a Língua Brasileira de Sinais - Libras), valorizam a história, arte e literatura que caracterizam uma comunidade com cultura e linguagem própria. A essas concepções, Tinti (2017), Magnani (2007) e Lopes; Veiga-Neto, (2006) descrevem que, as comunidades surdas são espaço de partilha (cultura, arte e língua) e a concepção da ideia de comunidade tem por base os vínculos simbólicos que representam os interesses comuns, propostas coletivas, a delimitação de espaços de existência constituída por uma minoria linguística e por marcas culturais próprias.

Com isso, o estabelecimento das comunidades surdas apresenta-se como uma ruptura dos movimentos hegemônicos (ouvintes), que forçam novas práticas e concepções a repeito da surdez, configurando-se puramente como uma resistência, expressão e identidade. Uma ação que significa que, pertencer à comunidade surda é estabelecer interação com o mundo surdo e ouvinte, formada por diferentes indivíduos, e, representada por distintos espaços, como: associações, escolas, grêmios, instituições, eventos, espaços de convívio, ambientes virtuais, reuniões familiares, etc. (PERLIN; MIRANDA, 2003; TINTI, 2017).

A partir desses preceitos, as pessoas que não se identificam com a cultura e comunidade surda seriam caracterizadas como "pessoas com DA". Nesse aspecto, a usabilidade do conceito, evidencia a ausência da capacidade auditiva e a correspondência sobre os aspectos da não utilização/identificação com a língua de sinais.

A firmação desses conceitos deu-se a partir da sistematização conceitual dos artigos tratados, em que percebemos que, compreender todas as características de identificação são processos que influenciam as propostas e práticas escolares. Isso porque, de acordo com cada construção de identidade e pertencimento, influenciados a partir das experiências que cada indivíduo estabeleceu no decorrer da vida, assim como também, o significado que cada um atribui ao status classificatório que determina o déficit, ou a perda da capacidade auditiva, é que as práticas escolares se desenvolverão.

Intrínseco nessa conceituação, o processo de construção da aprendizagem dá-se justamente à capacidade de percepção e autodescoberta. Para a criança com surdez, os pressupostos perpassam algumas características subjetivas da construção simbólica da comunicação. Lima et al (2006) destacam que a criança surda vivencia etapas da aquisição da linguagem oral assim como a criança ouvinte. 
Para autores como Vygostsky e Piaget a aquisição da linguagem tem papel fundamental e está relacionado ao desenvolvimento intelectual da criança. Apesar de concepções que divergem conceitualmente, os autores atribuem relação direta entre linguagem, raciocínio e pensamento.

Para esclarecer essa discussão, Vygotsky (1987) atribui a aquisição da linguagem do meio social como um resultado entre raciocínio e pensamento em nível intelectual. Piaget considerou a linguagem falada como manifestação da função simbólica, facilitadora, mas não necessária ao desenvolvimento intelectual. Nesse sentido, para Piaget, a linguagem reflete, mas não produz inteligência. (Fowler 1994, p.8).

Apesar das divergências, a linguagem apresenta-se como característica fundamental no processo de desenvolvimento da criança. Na ausência de ações que viabilizem estabelecer processos comunicativos e a linguagem, a criança apresentará dificuldades que interferirão diretamente no desenvolvimento das habilidades intelectuais. Isso significa que a criança com surdez, ao não receber estímulos que proporcionem comunicação por meio de conversas e estabelecimento entre símbolo e significado, permanecerá em um mundo isolado, em que as coisas ao redor não terão significado, nome, contexto e utilização. Será uma criança sem conhecimento de mundo, com dificuldade para compreender a si mesmo no universo.

$E$, contudo, para a propositura de práticas para todos, além de considerar os aspectos que correspondem à identidade da criança com surdez e o desenvolvimento das capacidades comunicativas a favor da aprendizagem, temos o paradigma do conceito da diferença. De acordo com dicionário de Língua Portuguesa, a palavra "diferente" significa: o que difere parcial ou totalmente; que não é semelhante, Igual ou idêntico; o que é distinto e variado.

A diferença compõe as características humanas: todo ser humano é diferente. São características especificas que nos tornam únicos. É justamente sobre essa temática que os movimentos inclusivos discutem: o direito e propostas humanas que possam favorecer e providenciar a igualdade de oportunidade, acesso, pertencimento, aprendizagem e trabalho para todos. Nesse sentido, a diferença é uma característica que permite que algo se distinga, se destaque. A diferença é o contrário da igualdade, e, quanto maior a quantidade de características ou qualidades não comuns, maior é a diferença.

Somos diferentes; temos diferentes percepções, sensações, simbólicas e conceituais. A diferença também está contida na oposição, na controversa, no dissenso. Na matemática a diferença é o resultado da subtração; o processo que diminui as quantidades, em que a quantidade resultante é a diferença. Autores como Mantoan (2004) discutem o aspecto da diferença nos âmbitos escolares e social. Freire (2013) destaca a importância de se ressaltar as diferenças a fim de se estimular o processo de conhecimento: são as características dos indivíduos os aspectos fundamentais para a aprendizagem. Alves (2003) enfatiza que as diferenças são as possibilidades em que podemos percorrer assuntos, ensinar e aprender. Rodrigues $(2015 ; 2006)$ salienta que nas diferenças estão contidas novas versões para interpretação do mundo.

Inegavelmente os processos históricos, escolares e sociais, em que a sociedade brasileira foi construída, supervalorizam espaços homogêneos e idealizados, por meio de uma sociedade organizada hierarquicamente a partir de padrões pré-estabelecidos. Ser diferente significa necessariamente ultrapassar o aspecto sociocultural e praticar a dimensão ética e política. Para isso, ressaltamos a ideia descrita por Matos e Mendes (2014) de que é necessário assegurar o trato democrático e público da diversidade, em que as diferenças não poderão ser socialmente hierarquizadas, mas destacar a identidade e as diferenças dos grupos que foram historicamente excluídos, para assim, desmistificar a ideia de inferioridade ao redor deles.

Entretanto, ressaltamos que a perspectiva da qualidade de ensino para todos, não descrimina pelas diferenças, mas que favorece a permanência e a aprendizagem daqueles que estão em idade escolar. Para que tal fenômeno aconteça é necessário que o docente utilize todas 
as ferramentas para a composição da prática pedagógica, para intervir de maneira construtiva no ensino a fim de proporcionar aprendizagem dos estudantes. (PIMENTA, 2013; 2005; 2002; 1999).

Biologicamente a criança com deficiência se distingue das demais: ela apresenta características que a destoa e destaca no contexto. Com isso, escolas, professores, familiares, e toda a sociedade, acabam por esperar que as crianças com deficiência apresentem índices iguais aos demais. Quando isso não acontece, a frustração perante o fracasso é inevitável e a diferença ressalta-se como impossibilitador da aprendizagem, do desenvolvimento e da aquisição de conhecimento. Isso geralmente acontece, pois fomos organizados a enxergar na diferença as características de segregação; em que ser diferente significa não pertencer. Quando a diferença supera as possibilidades, quando ela sobressai e marginaliza, como algo que ressalta a incapacidade, tudo o que for considerado "diferente" será excluído.

\section{CONCLUSÃO}

Pensar em ações verdadeiramente inclusivas é observar e perceber as diferenças, mas não ater-se a elas. As diferenças serão condutoras do processo que se estabelecerá, serão os eixos provedores de mudança. Para que as crianças com deficiência aprendam e tenham uma possibilidade de desenvolver todas as suas potencialidades, o aspecto da diferença será o propulsor, e as ações que se estabelecerem na condução das propostas educativas é que propiciarão a superação das dificuldades e aquisição do conhecimento. Toda ser humano é capaz de aprender.

\section{REFERÊNCIAS}

ALVES, R. Conversas sobre educação. Campinas, SP: Verus Editora, 2003

FOWLER, R. Piagentian Versus Vygotskyan Perspectives on Development and educacion. Estudo apresentado na Reunião anual da American Educacional Research Association, New Orleans, 1994.

FREIRE, P. Pedagogia do oprimido. Rio de Janeiro: Paz e terra, 2013. Brasília.

LEITE, Y. U. F.; DI GIORGI, C. A. G. Saberes docentes de um novo tipo na formação profissional do professor: alguns apontamentos. In: Santa Maria, v.29, n.2, p.135 - 145, 2004.

LIMA, D. M. C.; et. al. Educação Infantil: saberes e práticas da inclusão: dificuldades de comunicação e sinalização : surdez. [4. ed.] Secretaria de Estado da Educação do Distrito Federal... [et. al.]. - Brasília : MEC, Secretaria de Educação Especial, 2006.

LOPES, Maura C.; VEIGA-NETO, Alfredo. Marcadores culturais surdos: quando eles se constituem no espaço escolar. Perspectiva, Florianópolis, v.24, n.3, 2006. p. 81-100.

MAGNANI, José Cantor. "Vai ter música?": para uma antropologia das festas juninas de surdos na cidade de São Paulo. Ponto Urbe - Revista do Núcleo de Antropologia Urbana da USP, São Paulo, ano 1, 2007.

MANTOAN, M.T.E. O direito à diferença nas escolas. Revista pátio. 2004.

MENDES, E. G. A radicalização do debate sobre inclusão escolar no Brasil. In: Revista Brasileira de Educação v. 11 n. 33 set./dez. 2006. https://doi.org/10.1590/S1413-24782006000300002 
PATTO, M. H. S. O fracasso escolar como objeto de estudo: anotações sobre as características de um discurso. In: Cadernos de Pesquisa, São Paulo. 1988.

PATTO, M. H. S. Teoremas e cataplasmas no Brasil monárquico: o caso da medicina social. Novos Estudos CEBRAP, 44, 179-198. 1996.

PIAGET, J. Seis estudos de Psicologia, Rio de Janeiro: Forense, 1987.

PIMENTA, S. G. A construção da didática no GT da didática - análise e seus referenciais. In: Revista Brasileira de Educação, v.18, n.52, 2013. https://doi.org/10.1590/S1413-24782013000100009

PIMENTA, S. G. Formação de professores: identidade e saberes da docência. In: Saberes pedagógicos e atividade docente. São Paulo: Cortez, 1999, p.15-34.

PIMENTA, S. G. O estágio na formação de professores: unidade teórica e prática? 3. ed. São Paulo: Cortez, 2005.

PIMENTA, S. G.; GHEDIN, Evandro. O professor reflexivo no Brasil: gênese e critica de um conceito. 2a ed.São Paulo: Cortez, 2002.

RODRIGUES, D. (org.) Inclusão e Educação: doze olhares sobre a Educação Inclusiva, S. Paulo. Summus Editorial. 2006.

RODRIGUES, D. A usura da inclusão. In:Público [on-line] 2015. Disponível em: http://www.publico.pt/sociedade/noticia/a-usura-da-inclusao-1702324 Acesso: Julho/2017.

SCHLÜNZEN, E.T.M. Abordagem Construcionista, Contextualizada e Significativa: formação, extensão e pesquisa em uma perspectiva inclusiva. Tese (Livre Docência). Universidade Estatual Paulista, Presidente Prudente, São Paulo. 2015.

TINTI, M.C. A aprendizagem da criança com Deficiência Auditiva. Presidente Prudente: Unoeste Universidade do Oeste Paulista, 2017.

TINTI, M.C. Desenvolvimento profissional docente em uma perspectiva colaborativa: a inclusão escolar, as tecnologias e a prática pedagógica. Tese (Doutorado). Universidade Estadual Paulista, Presidente Prudente, São Paulo. 2016.

VALENTE, J. A. Espiral da aprendizagem e as tecnologias da informação e comunicação: repensando conceitos. In: JOLY, M. C. R. A. Tecnologia no ensino: implicações para a aprendizagem. São Paulo. Casa do Psicólogo, 2002. P.15-37.

VYGOTSKY, L.S. Pensamento e linguagem. São Paulo: Martins Fontes, 1987. 